\title{
Glass reinforced plastic (GRP) a new emerging contaminant - first evidence of GRP impact on aquatic organisms
}

\author{
Corina Ciocan ${ }^{1}$, Petra Kristova ${ }^{1}$, Claude Annels $^{1}$, Mael Derjean ${ }^{1}$ and Laurence Hopkinson ${ }^{2}$ \\ ${ }^{1}$ University of Brighton, School of Pharmacy and Biomolecular Sciences, Brighton, BN2 4GJ, UK \\ 2 University of Brighton, School of Environment and Technology, Brighton, BN2 4GJ, UK
}

\begin{abstract}
Plastics and synthetic materials are polluting the world's oceans. In this study we exposed juvenile mussels, Mytilus edulis, to glass reinforced plastic (GRP) dust, under laboratory conditions. The study ran for a period of 7 days, to test for the morphological and potential physiological impacts of GRP. Infrared spectroscopy has revealed that the GRP resin material is poly diallyl phthalate. In mussels, particulate glass and plastics were detected in the digestive tubules and gills, with a suite of inflammatory features observed in all examined organs. In parallel, we observed the effect of powdered GRP on swimming behaviour and survival of water fleas, Daphnia magna. Polymer particles and fibreglass adhered to the filament hairs on appendages, including the caudal spine, in exposed organisms. Most importantly, swimming impairement and sinking of the animals were recorded shortly after exposure. The potential implications for severe localized impact of GRP on aquatic environment are discussed.
\end{abstract}

Keywords: glass reinforced plastic, mussels, inflammatory reaction, swimming impairement

Coresponding author: Dr. Corina Ciocan $\underline{\text { C.Ciocan@brighton.ac.uk }}$

This work was supported by UKRI through the University of Brighton Ignite award to Dr.Corina Ciocan.

\section{Introduction}

Glass reinforced polymer (GRP) is a thermoset polymer-based composite that dominates the global boat market. As of 2011, GRP accounted for more than $80 \%$ of overall marine composites demand (Dokos, L. 2013).

GRP was created in the 1930s and made commercially available for boat production from the 1950s. Hulls for small boats, produced by hand lay-up, were one of the first applications of fibreglass. Nowadays, all types of boats including rigid inflatable boats (RIBs), large 
multihulls, canoes, warships and fast catamarans are using this versatile material (Marsh, 2006). Most of the GRP boats still survive to this day. However, a growing number of end-oflife vessels, no longer financially viable, have substantially limited options for their disposal, bar landfill. Recent studies by Rees et al, 2014 and Turner et al, 2016 highlighted the increasing environmental impact of the abandoned boats in UK estuaries. The authors reported that abandoned boats are a common site around UK coasts, apparently due to the lack of any clear and enforceable regulation. The potential environmental impacts of such decaying structures range from navigational hazard, crushing and smothering benthic communities, to contamination of surrounding areas.

A recent report published by the International Maritime Organization (IMO) in 2019 recognizes that numerous bodies (user groups, government, industry) have undertaken studies to consider disposal options of GRP boats. A fully viable market for the material is curremtly lacking, as the price for recycled fibreglass is too low to promote a recycling industry. Therefore, the sole legal option of disposal is landfill, which is restricted in some countries, leading to disposal at sea becoming more and more common (IMO report, 2019).

The damage to mangrove, seagrass and coral habitats from abandoned vessels have been recently investigated (Koch et al 2009, Graham and Nash, 2013) and although the effects have been recorded on a relatively localised basis, the cumulative effect from the practice may increase as disposal of end-of-life vessels is predicted to increase.

The chemical and biological effects of GRP vessel disposal at sea are yet to be revealed. There are several contaminants associated with abandoned vessels in benthic / pelagic ecosystems, e.g. hydrocarbons, heavy metals, flame retardants. It is reasonable to assume that GRP can break down to microplastics and fibre glass; moreover, microparticles can be released when the boats are crushed, dismantled or just repaired (IMO report 2019). In theory, the GRP fragments have higher density than sea water and will tend to concentrate nearshore, close to boatyards or where vessels are abandoned, disposed of or wrecked (GESAMP 2015).

Fiberglass has similar chemical and physical properties to asbestos: minerals which can be separated into thin, long fibres composed of $\mathrm{Si}$ and $\mathrm{O}$, as well as other inorganic materials (Galimany et al, 2009). Human exposure to both types of materials can cause fibrosis, lung cancer and mesothelioma by inhalation (Maxim and Maxim, 2001).

Precise data on the breakdown of GRP and the scale of contamination is just not available at the moment. However, as with other plastics we can assume that microparticles released from GRP (fibre glass and microplastics) can potentially accumulate into the food chain by zooplankton and filter feeders, and biomagnify to and in higher organisms (Wright et al, 2013).

In this study, the zooplaktonic crustacean Daphnia magna and benthic bivalve, the blue mussel Mytilus edulis were exposed to powdered GRP, to test the hypothesis that GRP dust will impact the physiology and health of both organisms. The GRP fragments, very similar to the material resulting from cutting and sanding operations carried out in normal boatyards were investigated by Raman and infrared spectroscopies. To demonstrate the effects, we 
performed a histological analysis to identify the presence of GRP in mussel tissues and to screen for potential pathology. Daphnia magna, a well-known model species representative for zooplankton and one of the lower levels of the food chain, was analysed for signs of ingestion or/and acute immobilization following short exposure to GRP. Since the knowledge on the presence and effects of GRP in aquatic environment is extremely limited, our approach follows the precautionary principle and aims at identifying preliminary first detectable effects of the contaminant, before evaluating the risk at environmentally relevant concentrations in retrospect. This study thus provides a basis for future research on GRP impacts in aquatic ecosystems, especially in relation to possible implications for transfer up the food chain.

\section{Materials and methods}

\subsection{IR and Raman spectroscopy}

A common type of laminated GRP containing layers of fibre-rich horizons sheet sourced from a local boatyard in Chichester Harbour was manually milled cut to produce a powder (Fig. 1). This fabricated powder has been further analysed by IR and Raman spectroscopy and particle size analysis and used for comparison. Mid-infrared measurements were performed using a Perkin Elmer, Spectrum 65 spectrometer, fitted with an attenuated total reflectance (ATR) accessory employing a ZnSe crystal. Measurements through the ATR accessory requires firm contact between the sample and the ZnSe crystal. This was achieved by uniform light manual compaction. The samples were measured in the spectral range $2000-550 \mathrm{~cm}^{-1}$ at a resolution of $4 \mathrm{~cm}^{-1}$. Each spectrum was collected from 16 scans and repeated on different subsamples to assure representative spectral information.

Raman analyses were conducted using a Perkin Elmer Raman Identicheck fitted with a 785 $\mathrm{nm}$ diode laser and with a CCD detector, thermoelectrically cooled to $-50{ }^{\circ} \mathrm{C}$. The measurements were acquired utilizing a fibre optic probe (spot size of $100 \mu \mathrm{m}$ at a working distance of $7.5 \mathrm{~mm}$ ) with $100 \mathrm{mV}$ laser power. Raman spectra were taken in the spectral range $2300-200 \mathrm{~cm}^{-1}$ at a resolution of $2 \mathrm{~cm}^{-1}$. Each spectrum was collected from 8 scans for 1 second utilising $80 \%$ of laser power and repeated six times on different randomly selected subsamples to assure representative spectral information. The limit of detection for the Raman system operating on pressed powders is ca. $2 \mathrm{w} / \mathrm{w} \%$ or better (Kristova et al., 2013). All analyses were conducted at $25^{\circ} \mathrm{C}$, at atmospheric pressure at the University of Brighton U. K.

Particle size analysis was performed by laser diffraction using a Malvern Mastersizer 3000 particle size analyser with a single optical measurement path. The particle sizer is equipped with series of detectors measuring the intensity of light scattered by the particles within the sample for both red and blue light wavelengths and over a wide range of angles. GRP sample was measured utilising small volume unit (100ml volume) over size range $10 \mathrm{~nm}-$ $3.5 \mathrm{~mm}$. Powdered GRP particles $(5 \mathrm{mg}$ ) were suspended in $20 \mathrm{ml}$ deionised water with trace 
of surface active agent (Tween 20, VWR) in concentration of 1 drop of Tween 20 per 2.5 litre water and sonicated for 2 minutes to improve dispersion/reduce agglomeration. This suspension was then introduced to further $80 \mathrm{ml}$ deionised water with no additives inside small volume unit circulating through particle size analyser.

\subsection{Mussel exposure to GRP: sample collection and exposure experiment}

Blue mussels Mytilus edulis were collected manually in January 2020 at low tide from Hove beach, East Sussex, UK $(50.823797,-0.173423)$. Mussels were sampled from one population only, kept on ice after collection, and transferred immediately to the laboratory. The animals were cleaned by removing the dirt and organic materials including algae and barnacles and then placed in a container with artificial seawater (Instant Ocean ${ }^{\circledR}$ Sea Salt, USA) for acclimatisation. During acclimatisation ( 3 days), the mussels were kept in the cold room (water temperature $5^{\circ} \mathrm{C}$ ) and fed daily with a $500 \mu \mathrm{L}$ dose of green algae Tetraselmis sp. culture suspension (ReefBoost, UK) per 5 litres of artificial seawater.

Mussels used in the exposure experiments were selected based on their size range $(25 \mathrm{~mm}$ to $35 \mathrm{~mm}$ ) and artificial seawater (Instant Ocean ${ }^{\circledR}$ Sea Salt, USA) was prepared to ensure a salinity of approximately $30.5 \mathrm{ppt}$. A total of 6 tanks ( 2 replicates per tank) were used to accommodate 60 mussels (10 mussels per tank): control, treatment 1 (0.3 g GRP per $5 \mathrm{~L}$ of water) and treatment 2 ( $0.6 \mathrm{~g} \mathrm{GRP}$ per $5 \mathrm{~L}$ of water). All tanks were fitted with aerators and the water temperature, $\mathrm{pH}$ and oxygen content were recorded daily.

A GRP sheet was manually milled cut to produce a powder, which was collected in a small beaker. The GRP powder contained fragments of microplastics and glass within a size range of 40-4000 $\mu \mathrm{m}$ (Fig. 1 and Fig. 4).

The pre-selected quantity of GRP was added to the exposure tanks (T1 and T2 only). The artificial seawater was changed once after 72 hours and the tanks were cleaned; the GRP powder was then added to $\mathrm{T} 1$ and $\mathrm{T} 2$ and the experiment was terminated after 7 days. No mortalities were registered in any of the tanks.

\subsection{Histopathology}

Histological analysis was employed to determine the potential presence of GRP within mussel tissues and to examine the pathological conditions present in selected organs. Mussel tissues were processed prior to histological examination following a technique adapted from Ciocan et al. (2010). Approximately $1 \mathrm{~cm}$ cube of each gonad were fixed in neutral buffered formaldehyde (Sigma-Aldrich) in clean tubes. Prior to wax infiltration, tissues were placed into labelled cassettes and processed through series of dehydration and clearing using an automated tissue processor (Leica Biosystems, Germany). After paraffin embedding, solid blocks were sectioned using a manual microtome (Thermo Scientific, UK). Sections of $7 \mu \mathrm{m}$ were transferred to slides and placed in a $37{ }^{\circ} \mathrm{C}$ oven overnight to ensure 
the tissue fixation to slides. Histo-Clear ${ }^{\mathrm{TM}}$ (National Diagnostics ${ }^{\mathrm{TM}}$, UK) and descending concentrations of ethanol were used to remove paraffin from sections. After staining with hematoxylin (Sigma-Aldrich) and eosin (Sigma-Aldrich), deparaffinized sections were then dehydrated and mounted in DPX (CellPath, UK). Histological examination of tissues was performed using a light microscope (Leitz Wetzlar, Germany) (40x/100x), and histopathological conditions were recorded along with micrographs corresponding to each condition using GXCam Hichrome-Lite (GT Vision, UK).

\subsection{Swimming impairment test}

The pelagic copepod Daphnia magna (water flea) were procured from Blades Biological Ltd, UK. Samples were stored in the laboratory, at room temperature and used within 3 days. We selected only mature animals and in order to avoid contamination, we used glass material for handling of particles, handling and accommodating of daphnids and for exposure experiments. Experimental tanks were covered to reduce airborne contamination. Daphnia were maintained in RO filtered water at $20^{\circ} \mathrm{C}$; approximately 30 adults were selected for each experimental tank: Control, treatment 1 ( $0.3 \mathrm{~g}$ GRP per $5 \mathrm{~L}$ of water) and treatment 2 ( $0.6 \mathrm{~g}$ GRP per $5 \mathrm{~L}$ of water); two replicates per each tank. The tanks were aerated prior to the addition of the daphnids.

Fig. 1. Glass Reinforced Polymer. A - fragment of a GRP flat sheet, B - powder obtained through cutting, collected in a Petri dish; scale bars $1 \mathrm{~cm}$. C and D - GRP powder $\times 50$ magnification.

The testing procedure was based on the OECD guideline Daphnia sp. (OECD, 2004). This guideline aims at identifying critical acute effect and threshold concentrations of chemicals towards daphnids. According to the guideline, the fraction of immobilised organisms is the criterion for acute adverse effects.

To explore the swimming behaviour and external adherence of microplastics on Daphnia, we first exposed the copepod to GRP powder for 90 minutes and then employed light microscopy to visualize the micro- fragments clumping on the carapace and appendages.

\section{Results}

\subsection{Raman and Infrared analysis of GRP fragments}

The mid-infrared spectrum of the GRP powder (Fig. 2) shows large number of peaks of different intensities and with many bands overlapped. Several strong high intensity peaks associated with carbonyl functional group at $1723 \mathrm{~cm}^{-1}$ (assigned to carbonyl stretch $\mathrm{C}=\mathrm{O}$ ), $1256 \mathrm{~cm}^{-1}$ (C-O-C), and $698 \mathrm{~cm}^{-1}$ (possibly O-CO-C). The spectrum also shows numerous bands associated with presence of aromatic ring(s) i.e. stretching of $C=C$ double bond $(1600$ 
$\mathrm{cm}^{-1}$ ) and vibrations associated with deformations of aromatic ring(s) at 1064, 987 and 742 $\mathrm{cm}^{-1}$. Other bands were assigned to stretches $\mathrm{C}-\mathrm{CH}_{3}$ e.g. 1452 and $1379 \mathrm{~cm}^{-1}$. A comparison with a spectroscopic library (Perkin Elmer, polymer library) was also performed and provided a close profile match with poly diallyl phthalate (PDP) which is a common polyester resin (0.86 search score).

The corresponding Raman spectrum of the powder shows numbers of sharp generally high intensity bands which are assigned to PDP (Fig. 3), including the sharp high intensity band at $1000 \mathrm{~cm}^{-1}$ which coincides with an identical high intensity spectral feature in the Renishaw spectral data base of polymers. However, the Raman spectrum of the powder also shows a range of generally low to very low intensity broad bands which cannot be readily ascribed to PDP (Fig. 3).

In the $200-600 \mathrm{~cm}^{-1}$ region bands at 222,414 and at $552 \mathrm{~cm}^{-1}$ are clearly resolved. The later band appears multi-component in nature (Fig. 3). The origin(s) of these bands are uncertain. However, a band around $c a 430 \mathrm{~cm}^{-1}$ is consistent with a silica-based glass and is widely assigned to a symmetrical motion of bridging oxygens (BO) in the plane bisecting Si-O-Si bonds (McMillan and Piriou 1983). Although pure vitreous silica does not show a corresponding band at $223 \mathrm{~cm}^{-1}$. Of the multitude of possible types of silica-based glasses (e.g., McMillan and Piriou 1983; Yadav and Singh 2015), bands have been reported at 412 $\mathrm{cm}^{-1}, 544 \mathrm{~cm}^{-1}$ and $622 \mathrm{~cm}^{-1}$ from aluminosilicate glasses in conjunction with a band at 222 $\mathrm{cm}^{-1}$ (Yadav and Singh 2015). In which the three high wave number bands are assigned to bending vibrations of the bridging oxygen (BO) bonds of $\left[\mathrm{SiO}_{4}\right]$, whereas the band at $222 \mathrm{~cm}$ ${ }^{1}$ is assigned to the vibrations related to the $\mathrm{Na}^{+}$cation (Yadav and Singh 2015). The same authors also report a band near $779 \mathrm{~cm}^{-1}$ caused by the $\mathrm{Si}-\mathrm{O}-\mathrm{Si}$ network and $\left[\mathrm{AlO}_{4}\right]$ units. The Raman spectrum of the powder shows a similar low intensity broad band in the same spectral vicinity, and a second low intensity band at ca $840 \mathrm{~cm}^{-1}$ (Fig. 3). The origin of this band is uncertain but bands in the range of $c a 820 \mathrm{~cm}^{-1}$ have been reported with slight wavenumber variation for specific aluminosilicate glass types (Yadav and Singh 2015). Likewise, low intensity broad bands at $c a 1074 \mathrm{~cm}^{-1}$ and $1186 \mathrm{~cm}^{-1}$ could be assigned to Si-O stretching vibrations of $\left[\mathrm{SiO}_{4}\right]$ tetrahedra (e.g., Yadav and Singh 2015).

The experimental powder also shows a prominent broad intensity high at $c a 1868 \mathrm{~cm}^{-1}$. The origin of this spectral feature is unclear, it does coincide with an infrared active band assigned to a $\mathrm{v}^{\prime \prime}{ }_{\text {asym }} \mathrm{Si}-\mathrm{O}-\mathrm{Si}+\mathrm{v}_{\text {sym }}$ Si-O-Si combination mode in an $\left[\mathrm{SiO}_{2}\right]$ based glass matrix (Efimov and Poggareva 2006). Accepting this it also follows that a variety of second order combinations originating from the silicate glass may also contribute to the 'intensity high' apparent background in the $1450-1650 \mathrm{~cm}^{-1}$ region. Hence available evidence suggests that an aluminosilicate glass (presumably in the form of the fibre content of the GRP) is present within the PDP binding resin. 
Fig. 2. Mid infrared spectrum of powdered GRP. Band assignments for some major poly diallyl phthalate (PDP) peaks are highlighted. Mid-infrared measurements were performed using a Perkin Elmer, Spectrum 65 spectrometer, samples were measured in the spectral range $2000-550 \mathrm{~cm}^{-1}$ at a resolution of $4 \mathrm{~cm}^{-1}$.

Fig. 3. Raman spectrum of powdered GRP. poly diallyl phthalate (PDP) peaks are highlighted alongside wavenumber values listed in the Perkin Elmer, polymer library. Bands not assigned to PDP are discussed in the text. Raman analyses were conducted using a Perkin Elmer Raman Identicheck, and the Raman spectra were taken in the spectral range $2300-200 \mathrm{~cm}^{-1}$ at a resolution of $2 \mathrm{~cm}^{-1}$.

\subsection{Particle size analysis}

Particle size analysis of the fabricated powdered GRP material indicates a measured mode grain size of $40 \mu \mathrm{m}$ (by laser diffraction). The measured sample shows a polydisperse size distribution profile consistent with microscopic evidence and possible agglomerations of particle aggregates (Fig. 4). Three subsamples were measured, average $d v(50)$ calculated as $58.2 \mu \mathrm{m}(\mathrm{SD} 8.9 \mu \mathrm{m})$ and average $\mathrm{D}[3,2] 40.5 \mu \mathrm{m}$ (SD $4.3 \mu \mathrm{m})$.

Fig. 4. Particle size distribution of fabricated GRP powder measured by laser diffraction.

\subsection{Mussel Histopathology}

Animals in the control group did not express any of the pathologies (Fig. 5). The micrographs of histopathological conditions recorded in the observation are shown in Figure 6. Figures $A$ and $B$ show a section of a digestive gland with particulate matter accumulated in the stomach. A small shard can be seen in figure $6 \mathrm{C}$, embedded in the connective tissue, in the mantle. Inflammatory reactions were detected in more than $60 \%$ of animals exposed to GRP, mostly in the gills and gonad tissues (Fig.6 D,E,F). Almost a third of exposed mussels presented excess lipid accumulation in the mantle and gills. No differences in the frequency of the recorded pathologies were observed between the two treatments (T1 and T2). 
Fig. 5. The occurrence of histopathological conditions observed in the gonad tissue of mussels exposed to GRP for 7 days ( $n=10)$. The treatments were as follows: Control, T1 $(0.3 \mathrm{~g} / 5 \mathrm{~L}), \mathrm{T} 2(0.6$ $\mathrm{g} / 5 \mathrm{~L})$.

Fig. 6. Histopathological conditions in mussel tissues after exposure to GRP powder. Sections of 7 $\mu \mathrm{m}$, stained with hematoxylin and eosin. $(A, B)$ digestive gland, fragments of GRP particles accumulated in the stomach; (C) fiberglass shard embedded in the connective tissue in the mantle; (D) inflammation of the gills, hemocytes invading the gill filaments; $(E, F)$ egg follicles, female gonad, inflammation of the gonad; Arrows point to each pathological condition. Magnification X 100 $(A, D, E, F), X 400(B, C)$.

\subsection{Swimming impairment test}

Light microscopy analysis confirmed that microplastics and fibreglass adhere to the external appendages of the zooplankton: small polymer fragments (less than $50 \mu \mathrm{m}$ ) were clumped around the caudal spine and carapace segments of live copepods (Fig.7). Those fragments contributed to a considerable increase of the organism weight and therefore their sinking rate, resulting in the sinking of $100 \%$ of the animals in the exposure groups, after only 90 min. No ingestion of the GRP particles has been detected after the short exposure experiment.

Fig. 7. Microplastic of different sizes adhere to zooplankton. A - microplastics trapped between the hairs of caudal spine; size bar $50 \mu \mathrm{m}$. B - Microplastics and glass fibres surrounding Daphnia, with small fragments trapped on the carapace; size bar $500 \mu \mathrm{m}$. C - microplastics clumped around the head and the compound eye.; size bar $100 \mu \mathrm{m}$.

\section{Discussion}

Our laboratory toxicity tests with $D$. magna and $M$. edulis exposed to GRP dust for a short period of time revealed morphological and physiological damage in both species, ranging from inflamatory reaction to swimming impairement.

Recently, plastic particles have been shown to accumulate in various aquatic species, such as zooplankton (Desforgeset al, 2015) and filter feeders (Van Cauwenberghe et al., 2015), and therefore bioaccumulate and bio magnify in fish (Wright et al, 2013), or pass directly to larger planktonic feeding organisms such as basking shark and whales (Fossi et al., 2014). 
GRP powder is easily released during cutting or sanding of the fibre glass sheets from boats or other structures (tubing, pontoons, GRP made outdoor furniture) and contains both microplastics and glass fibres (Fig.1).

Infrared spectroscopy has revealed that the GRP resin material is poly diallyl phthalate. However any peaks for glass fibres were obscured by the numerous peaks of the PDP or were not visible in infrared spectra. Raman spectra showed lower signal to noise ratio and was less suitable for resin identification, however it was possible to confirm PDP material. Moreover Raman spectra showed some peaks associated with glass fibres identified as silica type glass.

PDP is a material commonly used in boat industry; it is deemed inert and resistant to moisture thanks to its polymerization, however, its monomer counterpart is considered an aquatic hazard (Ge et al, 2007). Chemical stability and inertness of the secondary PDP microplastics needs to be further investigated.

The noxious effects of fiberglass ingestion in organisms are poorly understood. To the best of our knowledge, the only study to reveal the uptake of glass fibres by mussels (Mytilus galloprovincialis L.) was published more than 10 years ago by Galimany et al., (2009). The authors recommended further research into prey-predator relationships, along with possible implications for human health and the health of the organisms themselves.

Our results show clear uptake of the material, both plastic and fibre glass by the blue mussels exposed for just 7 days to a small quantity of GRP powder (Fig. 6 A ,B). The impressive quantity of material accumulated in the digestive gland raises concerns related to the ability of the animals to further process normal food. Several recent studies have suggested that microplastics ingestion leads to blockage of the intestinal tract and later on to death through malnutrition and starvation, in a variety of species (Duncan et al, 2019; Deudero and Alomar, 2015). In a study by Gonzales-Soto et al. 2019, large microplastics were observed in the lumen of stomach and digestive tubules of exposed mussels (Mytilus galloprovincialis), but were also occasionally found also within the epithelial cells. The authors concluded that at the whole organism level, a hormetic effect is evident, as a potential compensatory mechanism, with exposed mussels significantly increasing their food absorption efficiency in order to make up for the energy expended dealing with stress. No data regarding environmental contamination with GRP has been published to date, however up to 7000 pieces of glass fibres per $\mathrm{Kg}$ flesh, have been identified in the digestive gland of oysters (Ostrea edulis) and mussels (Mytilus edulis), collected from a natural population, close to an active boatyard (Ciocan, unpublished results).

An additional concern regarding the aquatic contamination with GRP has been demonstrated in vitro by the adherence of GRP microparticles to the exoskeleton of Daphnia magna and the severe impact on their swimming capacity. Daphnids in the treatment tanks came into direct contact with the particles mainly by swimming to the water surface. Shortly after the start of the experiment, it became obvious that in the treatment groups, some particles would attach to the carapax and appendices, which 
impeded swimming for most of the indidviduals. Same results were reported in the case of surface coating by PS-beads (Cole et al., 2013) or nanoparticles (Dabrunz et al., 2011) experimental exposures. In their natural environment, daphnids move down- and upward in the water column, sometimes being able to free themselves from the particulate contaminants (Rehse et al, 2016). However, because of the very limited water depth under laboratory conditions, we registered a complete swimming incapacity in $100 \%$ of the water fleas in our exposed tanks, after only $90 \mathrm{~min}$.

Of further concern is the trophic-transfer: microplastics, fibre glass (and contaminants released from them) within lower-trophic, keystone organisms such as Daphnia may result in the trophic-transfer of these contaminants up the food-chain, with the potential for bioaccumulation and therefore severe consequences for higher trophic levels. All our copepods from the treatment group sank after the 90 min exposures. They were coated in microplastics and fibre glass, presumably because of hydrophobic- or static-attractions between the microfragments and organic material (Fig.7).

In live organisms, we also found that microplastics were becoming trapped between the external appendages and carapace segments; very small microplastics (less than $50 \mu \mathrm{m}$ ) became lodged between the filamental hairs of the dorsal spine and the fragments of the carapace. Microscopical examination revealed that the additional materials stuck on the exoskeleton may have had repercussions for locomotion and swimming behaviour in general, therefore limiting the ability of the organisms to detect prey, feed, reproduce, and evade predators, in the natural environment.

The term 'mineral fibre' evokes similarities with naturally occurring fibres (asbestos, erionite), which are the cause of various benign and malignant diseases (de Vuyst et al., 1995).

More recent research, such as Abbate et al. (2006), demonstrates that exposure to fiberglass contributes to the development of pathologic alterations of the respiratory apparatus, for which the etiopathogenesis and evolution are still unclear. The authors suggest that fibreglass - independent of the environmental concentration - causes an alteration of the cellular and enzymatic components of the deep lung, in working men employed in different GRP processing operations and exposed to production dusts. These studies may be relevant when it comes to disposing of end-of-life boats via extrusion; the dust produced in/near the marine environment, for example during dry dock boat repair, can pose very real risk of entering the water column and then the food web.

\section{Conclusions}

To our knowledge, this is the first report of the GRP spectroscopy fingerprint and exposure induced adverse effects on aquatic organisms. Our findings suggest that mussels and water fleas are affected by the GRP dust and they are potentially able to introduce this new contaminant in the food web. IR spectroscopy has revealed that the GRP resin material is 
poly diallyl phthalate. Phtalates have been acknowledged as potent toxicants, mainly associated with microplastics pollution. Further research should focus on the fate and effects of GRP in the aquatic environment and possible implications for human health.

\section{References}

Abbate, C., Giorgianni, C., Brecciaroli, R., Giacobbe, G., Costa, C., Cavallari, V., Albiero, F., Catania, S., Tringali, M. A., Martino, L. B., \& Abbate, S. 2006. Changes induced by exposure of the human lung to glass fiber-reinforced plastic. Environmental health perspectives, 114(11), pp. 1725-1729. https://doi.org/10.1289/ehp.8676

Ciocan C.M., Cubero-Leon E., Puinean A.M., Hill E.M., Minier C., Osada M., Fenlon K., Rotchell J.M. 2010. Effects of estrogen exposure in mussels, Mytilus edulis, at different stages of gametogenesis. Environ Poll 158, pp. 2977-2984.

DOI: $10.1016 /$ j.envpol.2010.05.025

Cole, M., Lindeque, P., Fileman, E., Halsband, C., Goodhead, R., Moger, J. and Galloway, T.S. 2013. Microplastic Ingestion by Zooplankton. Environ Sci \& Tech 47 (12), pp. 6646-6655 DOI: $10.1021 /$ es400663f

Dabrunz, A., Duester, L., Prasse, C., Seitz, F., Rosenfeldt, R., Schilde, C., Schaumann, G. E., \& Schulz, R. 2011. Biological surface coating and molting inhibition as mechanisms of TiO2 nanoparticle toxicity in Daphnia magna. PloS one, 6(5), e20112.

https://doi.org/10.1371/journal.pone.0020112

Desforges, J.W., Galbraith, M. \& Ross, P.S. 2015. Ingestion of Microplastics by Zooplankton in the Northeast Pacific Ocean. Arch Environ Contam Toxicol 69, pp. 320-330. https://doi.org/10.1007/s00244-015-0172-5

Deudero, S., Alomar, C. 2015. Mediterranean marine biodiversity under threat: Reviewing influence of marine litter on species. Mar Pollut Bull. 98(1-2), pp. 58-68.

DOI: 10.1016/j.marpolbul.2015.07.012

De Vuyst, P., Dumortier, P., Swaen, G.M.H., Pairon, J.C., Brochard, P. 1995. Respiratory health effects of man-made vitreous (mineral) fibres. European Respiratory Journal 8, pp. 2149-2173. DOI: $\underline{10.1183 / 09031936.95 .08122149}$

Dokos, L. (2013). Adoption of marine composites - a global perspective. Reinforced Plastics 57(3), pp. 30-32. 
Duncan, E.M., Arrowsmith, J.A., Bain, C.E. et al. Diet-related selectivity of macroplastic ingestion in green turtles (Chelonia mydas) in the eastern Mediterranean. Sci Rep. 9, 11581 https://doi.org/10.1038/s41598-019-48086-4

Efimov, A.M and Poggareva, V.G 2006. IR absorption spectra of vitreous silica and silicate glasses: The nature of bands in the 1300 to $5000 \mathrm{~cm}^{-1}$ region. Chem Geol 229, pp. 198-217. https://doi.org/10.1016/i.chemgeo.2006.01.022

Fossi, M.C., Coppola, D. Baini, M., Giannetti, M., Guerranti, C., Marsili, L., Panti, C., de Sabata, E. and Clò, S. 2014. Large filter feeding marine organisms as indicators of microplastic in the pelagic environment: The case studies of the Mediterranean basking shark (Cetorhinus maximus) and fin whale (Balaenoptera physalus). Mar Environ Res, 100, pp. 17-24. 10.1016/j.marenvres.2014.02.002

Galimany, E., Ramón, M., Delgado, M. 2009. First evidence of fiberglass ingestion by a marine invertebrate (Mytilus galloprovincialis L.) in a N.W. Mediterranean estuary. Mar Pollut Bull, 58, pp. 1334-1338. 10.1016/i.marpolbul.2009.04.027

Ge, R.S., Chen, G.R., Tanrikut, C., Hardy, M.P. 2007. Phthalate ester toxicity in Leydig cells: developmental timing and dosage considerations. Reprod Toxicol. 23(3), pp. 366-373. DOI: 10.1016/i.reprotox.2006.12.006

GESAMP, 2015. Sources, fate and effects of microplastics in the marine environment: a global assessment (Kershaw, P.J, ed.). Rep. Stud. GESAMP No.90. ISSN: 1020-4873

Graham, N.A.J. and Nash, K.L., 2013. The importance of structural complexity in coral reef ecosystems. Coral Reefs, 32 (2), pp. 315-326. DOI: 10.1007/s00338-012-0984-y

González-Soto, N., Hatfield, J., Katsumiti, A., Duroudier, A., Lacave, J.M., Bilbao, E., Orbea, A., Navarro, E., Cajaraville, M.P. 2019. Impacts of dietary exposure to different sized polystyrene microplastics alone and with sorbed benzo[a]pyrene on biomarkers and whole organism responses in mussels Mytilus galloprovincialis. Sci Total Environ, 684, pp. 548-566. https://doi.org/10.1016/i.scitotenv.2019.05.161

International Maritime Organisation, Report 2019. End-Of-Life Management of Fibre Reinforced Plastic Vessels: Alternatives to At Sea Disposal. Printed and bound CPY Group UK, Croydon.

Koch, E.W., Barbier, E.B., Silliman, B.R., Reed, D.J., Perillo, G.M.E, Hacker, S.D., Granek, E.F., Primavera, J.H., Muthiga, H., Polasky, S., Halpern, B.S., Kennedy, C.J., Kappel, C.V., Wolanski E. 2009. Non-linearity in ecosystem services: temporal and spatial variability in coastal protection. Ecosyst Serv, 7(1), pp. 29-37. https://doi.org/10.1890/080126 
Kristova, P., Hopkinson, L., Rutt, K., Hunter, H., Cressey, G. 2013. Quantitative analyses of powdered multi-minerallic carbonate aggregates using a portable Raman spectrometer. Am Mineral, 98, pp. 401-409. https://doi.org/10.2138/am.2013.4305

McMillan P. and Piriou B. 1983. Raman spectroscopic studies of silicate and related glass structure: a review. B Minéral, 106, pp. 1-2, DOI: https://doi.org/10.3406/bulmi.1983.7668

Marsh, G. (2006). 50 years of reinforced plastic boats. Reinforced Plastics 50 (9) pp. 16-19. https://doi.org/10.1016/S0034-3617(06)71125-0

Maxim, L.D and Maxim E.E., 2001. Interspecies Comparisons of the Toxicity of Asbestos and Synthetic Vitreous Fibers: A Weight-of-the-Evidence Approach. Regul Toxicol Pharm 33(3), pp. 319-42. https://doi.org/10.1006/rtph.2001.1467

OECD (2004), Test No. 202: Daphnia sp. Acute Immobilisation Test, OECD Guidelines for the Testing of Chemicals, Section 2, OECD Publishing, Paris, https://doi.org/10.1787/9789264069947-en.

Rees, A., Turner, A., Comber, S. 2016. Metal contamination of sediment by paint peeling from abandoned boats, with particular reference to lead. Sci Total Environ, 494, pp. 313319. https://doi.org/10.1016/i.scitotenv.2014.06.064

Rehse, S., Kloas, W. and Zarfl, C. 2016. Short-term exposure with high concentrations of pristine microplastic particles leads to immobilisation of Daphnia magna. Chemosphere, 153, pp. 91-99. DOI: 10.1016/i.chemosphere.2016.02.133

Turner, A. and Rees, A. 2016. The environmental impacts and health hazards of abandoned boats in estuaries. Reg Stud Mar Science, 6, pp. 72-75.

https://doi.org/10.1016/i.rsma.2016.03.013

Van Cauwenberghe, L., Claessens, M., Vandegehuchte, M.B. and Janssen, C.R. 2015. Microplastics are taken up by mussels (Mytilus edulis) and lugworms (Arenicola marina) living in natural habitats. Environ Pollut. 199, pp. 10-17.

DOI: 10.1016/i.envpol.2015.01.008

Wright, S.L., Thompson, R.C., Galloway, T.C. 2013. The physical impacts of microplastics on marine organisms: A review. Environ Pollut, 178, pp. 483-492. https://doi.org/10.1016/i.envpol.2013.02.031

Yadav, K. and Singh, P. 2020. A Review of Structure of Oxide Glasses by Raman Spectroscopy. Roy Soc Chem Adv. In press. https://doi.org/10.1039/C5RA13043C 

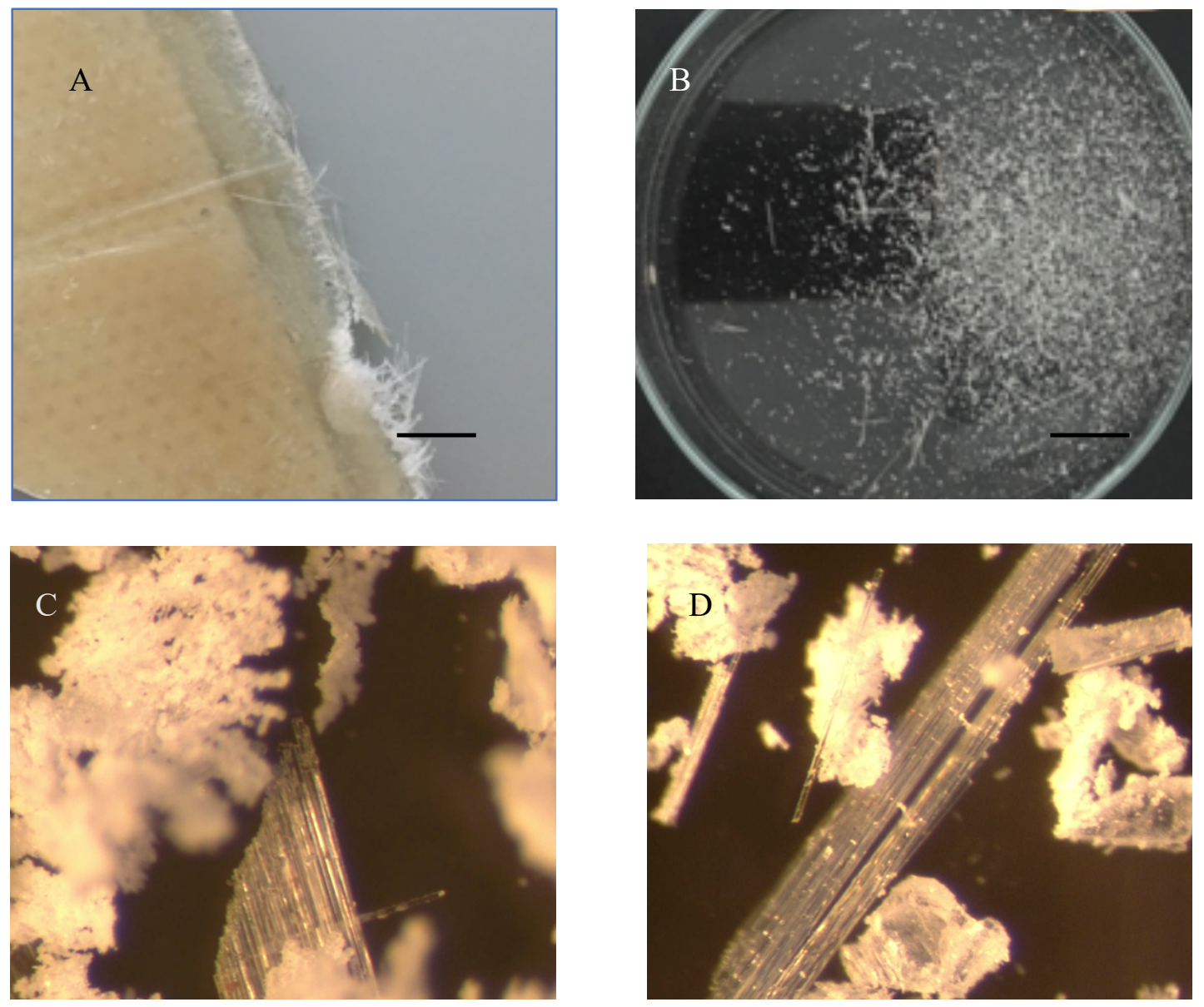

Fig. 1. Glass Reinforced Polymer. A - fragment of a GRP flat sheet, B - powder obtained through cutting, collected in a Petri dish; scale bars $1 \mathrm{~cm}$. C and D-GRP powder x 50 magnification. 


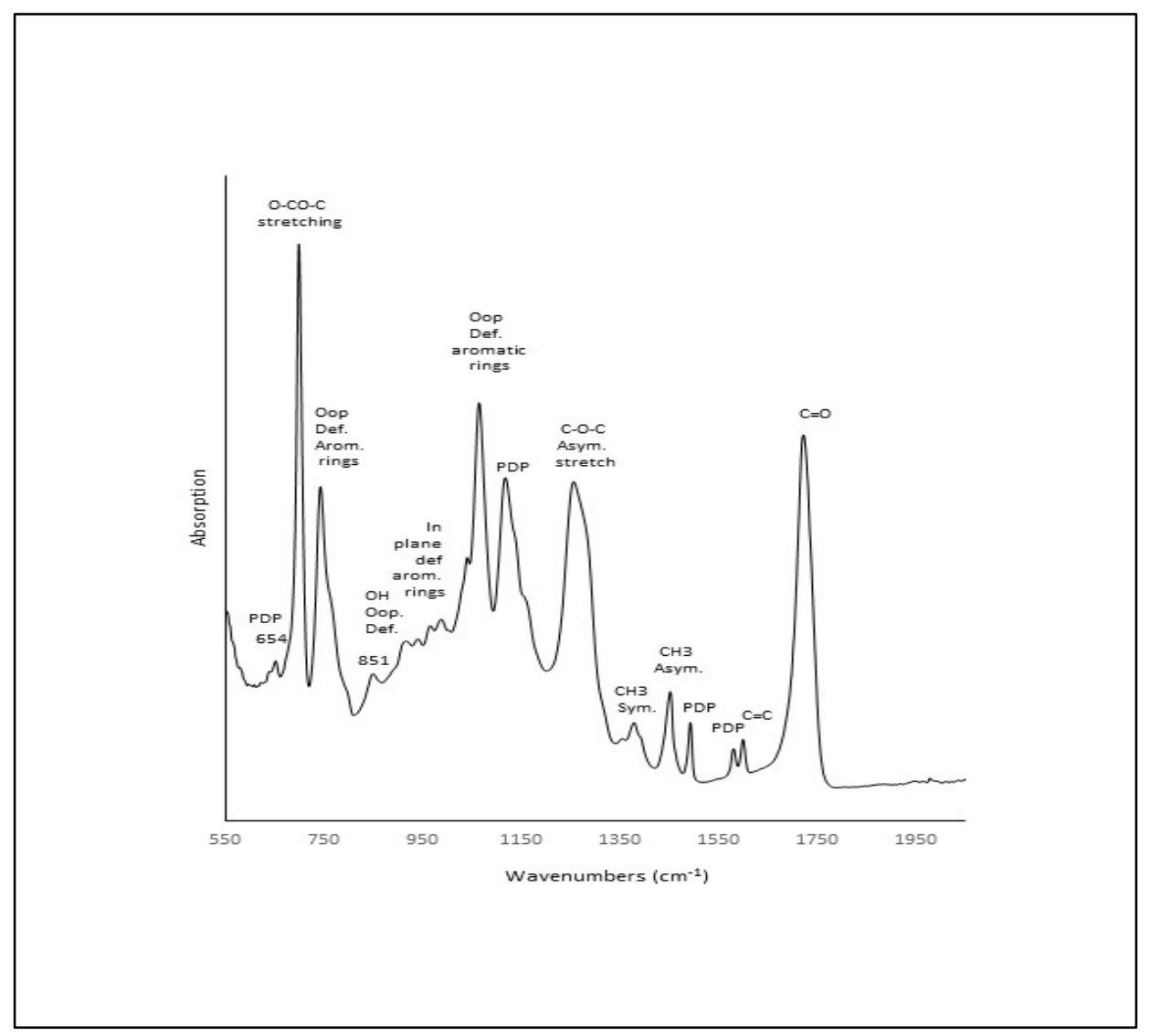

Fig. 2. Mid infrared spectrum of powdered GRP. Band assignments for some major poly diallyl phthalate (PDP) peaks are highlighted. Mid-infrared measurements were performed using a Perkin Elmer, Spectrum 65 spectrometer, samples were measured in the spectral range $2000-550 \mathrm{~cm}^{-1}$ at a resolution of $4 \mathrm{~cm}^{-1}$. 


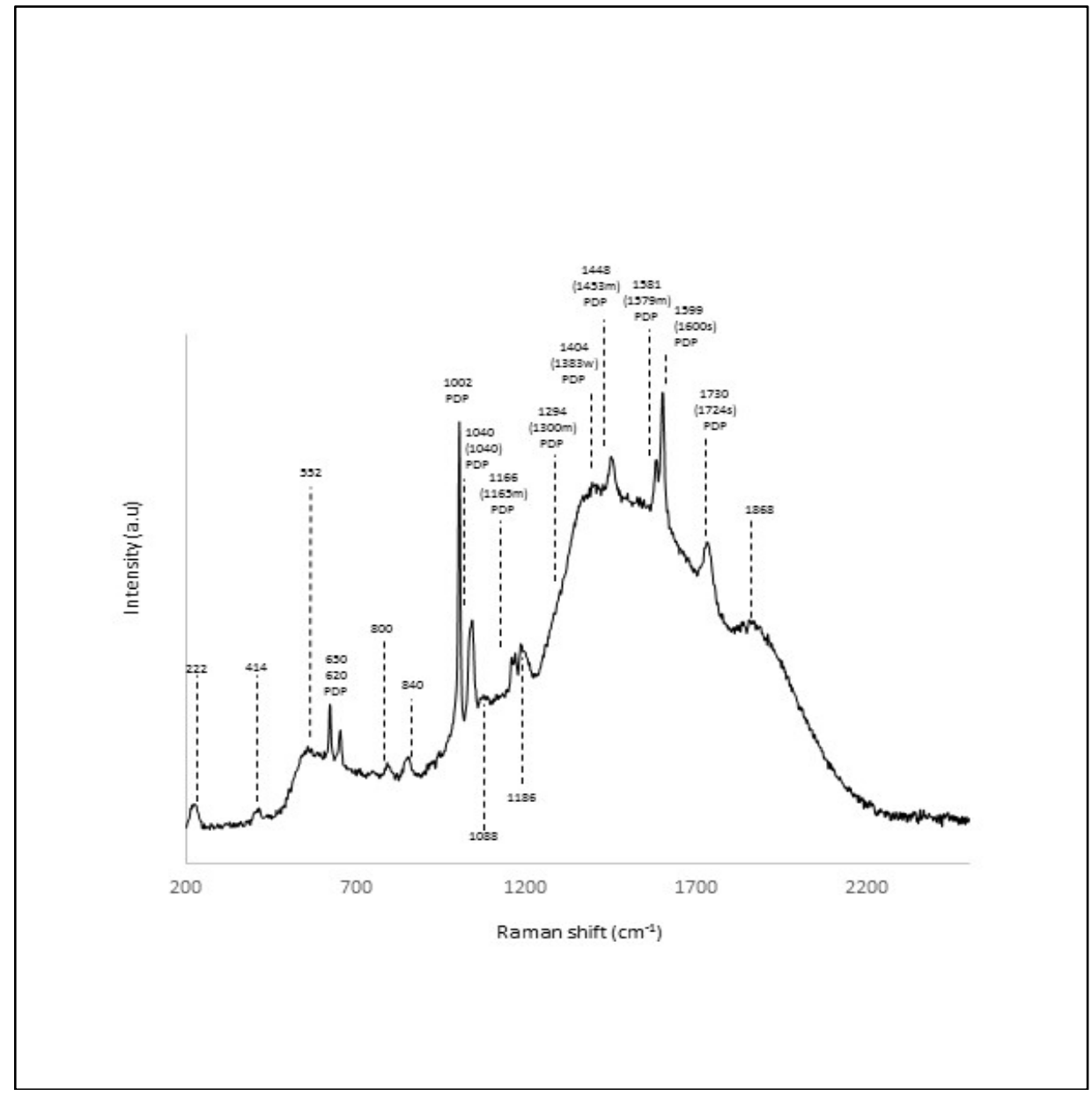

Fig. 3. Raman spectrum of powdered GRP. poly diallyl phthalate (PDP) peaks are highlighted alongside wavenumber values listed in the Perkin Elmer, polymer library. Bands not assigned to PDP are discussed in the text. Raman analyses were conducted using a Perkin Elmer Raman Identicheck, and the Raman spectra were taken in the spectral range $2300-200 \mathrm{~cm}^{-1}$ at a resolution of $2 \mathrm{~cm}^{-1}$. 


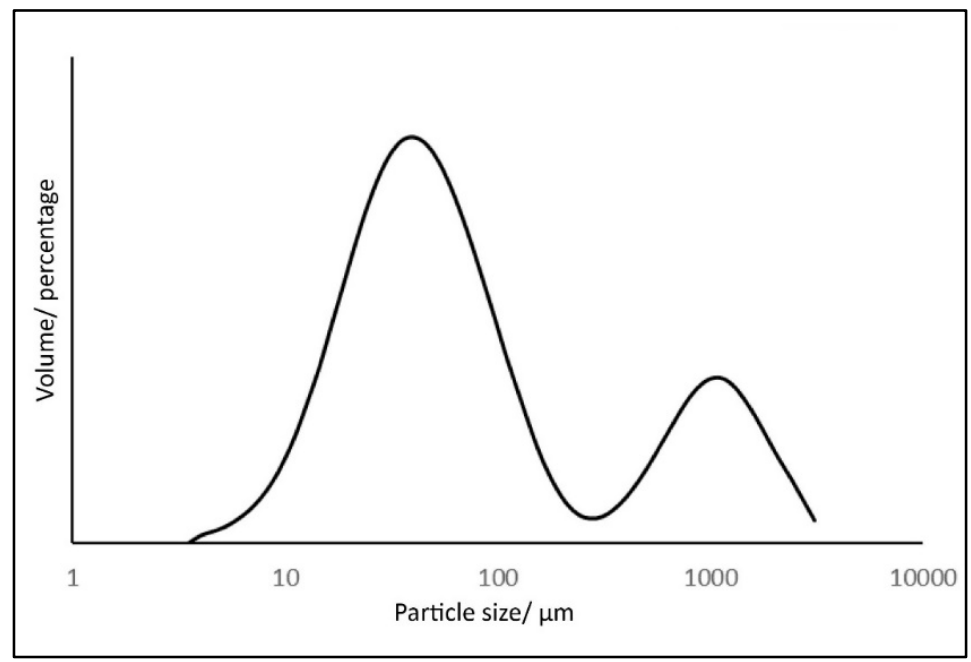

Fig. 4. Particle size distribution of fabricated GRP powder measured by laser diffraction. 


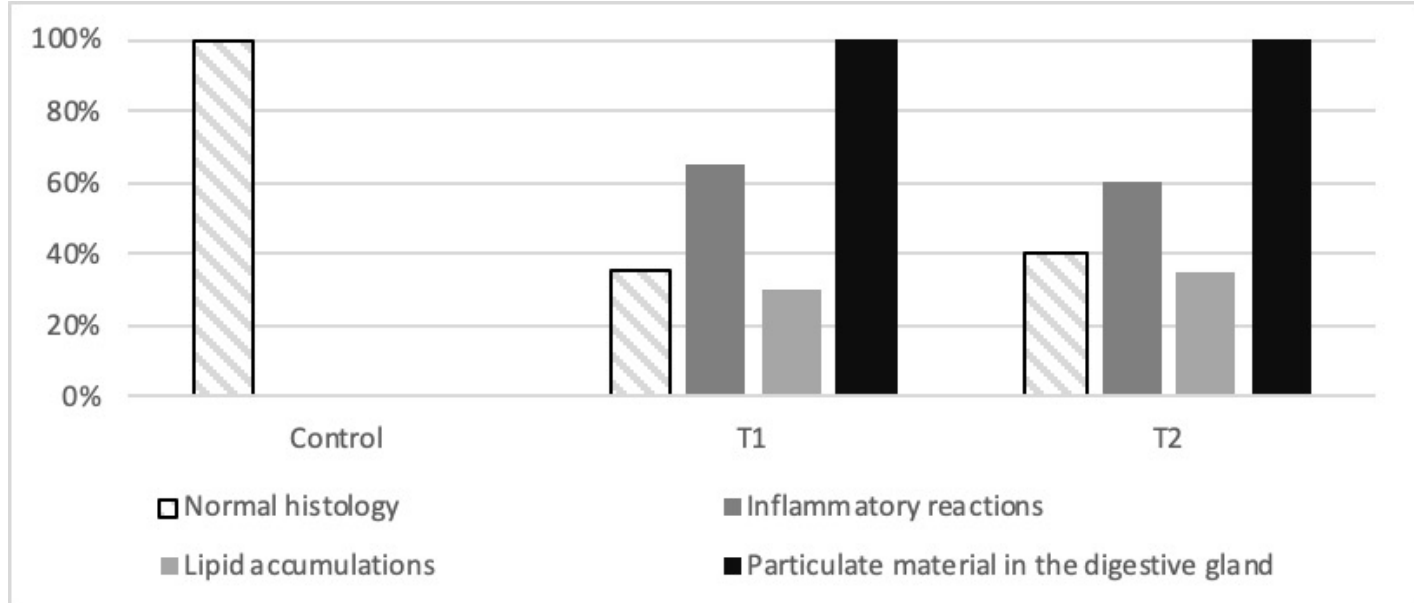

Fig. 5. The occurrence of histopathological conditions observed in the gonad tissue of mussels exposed to GRP for 7 days $(n=10)$. The treatments were as follows: Control, T1 $(0.3 \mathrm{~g} / 5 \mathrm{~L}), \mathrm{T} 2(0.6 \mathrm{~g} / 5 \mathrm{~L})$. 

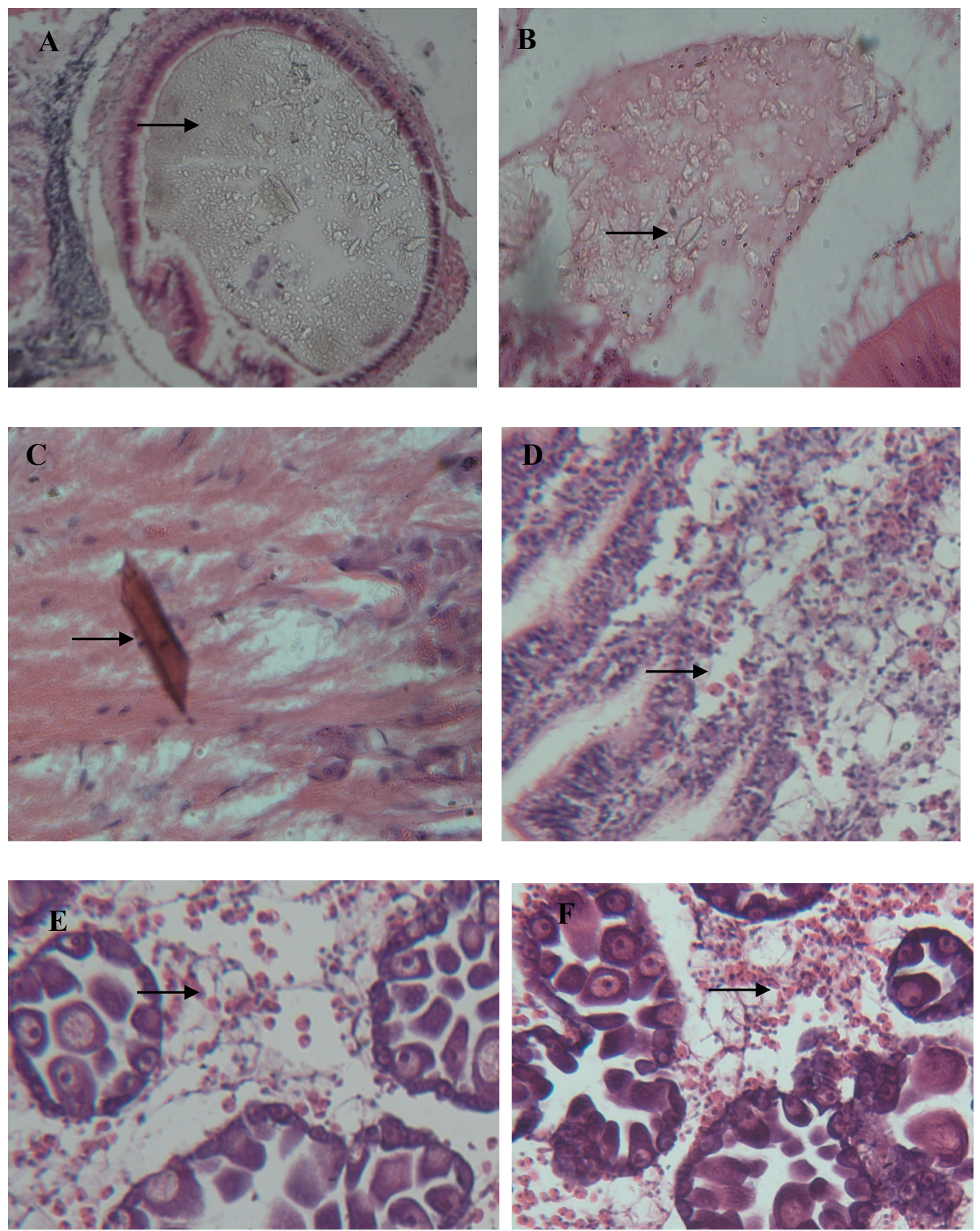

Fig. 6. Histopathological conditions in mussel tissues after exposure to GRP powder. Sections of $7 \mu \mathrm{m}$, stained with hematoxylin and eosin. $(A, B)$ digestive gland, fragments of GRP particles accumulated in the stomach; (C) fiberglass shard embedded in the connective tissue in the mantle; (D) inflammation of the gills, hemocytes invading the gill filaments; $(E, F)$ egg follicles, female gonad, inflammation of the gonad; Arrows point to each pathological condition. Magnification X $100(A, D, E, F), X 400(B, C)$. 

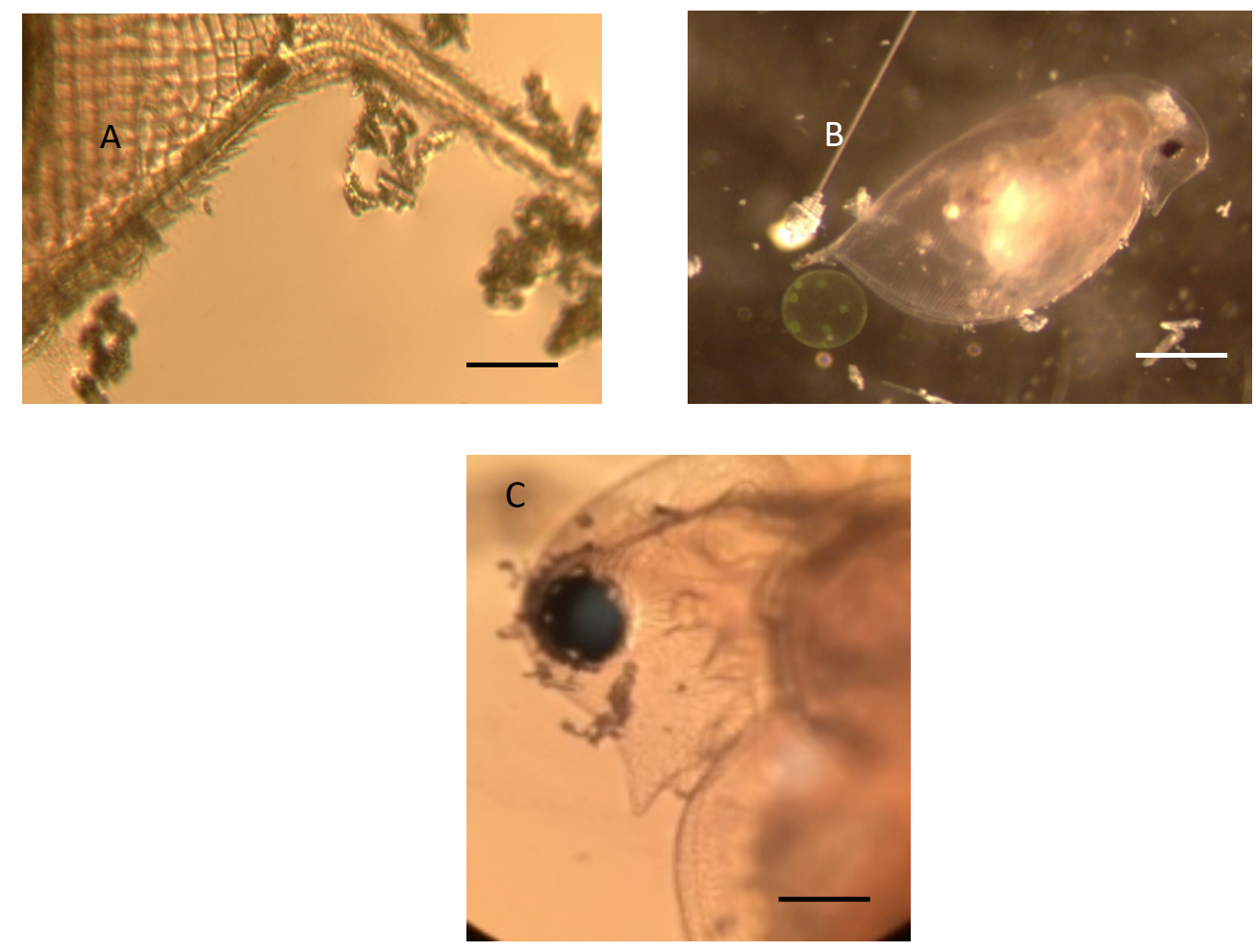

Fig. 7. Microplastic of different sizes adhere to zooplankton. A - microplastics trapped between the hairs of caudal spine; size bar $50 \mu \mathrm{m}$. B - Microplastics and glass fibres surrounding Daphnia, with small fragments trapped on the carapace; size bar $500 \mu \mathrm{m}$. C - microplastics clumped around the head and the compound eye.; size bar $100 \mu \mathrm{m}$. 


\section{Declaration of interests}

$\bigotimes$ The authors declare that they have no known competing financial interests or personal relationships that could have appeared to influence the work reported in this paper.

$\square$ The authors declare the following financial interests/personal relationships which may be considered as potential competing interests: 
${ }^{*}$ Credit Author Statement

CC: Conceptualization, Methodology, Supervision, Writing- Reviewing and Editing. PK: Investigation, WritingOriginal draft preparation. CA and MD: Investigation. LH: Conceptualization, Methodology, Supervision, Writing. 